\title{
A journal of useful epidemiology? The retiring editor looks back over five years
}

At the European Regional meeting of the International Epidemiological Association held in Münster in September 1997, a workshop addressed the impact of journals in disseminating epidemiological ideas and results. I had the opportunity of addressing an issue which was raised at the first Editorial Board meeting of this journal, which I chaired in 1993-members of our editorial board hoped that our journal would publish "useful" epidemiology.

This is not a straightforward issue. Indeed, over recent years many accusations have been made about epidemiologists over stretching themselves in trying to address-or even exert forceful influence on-policy issues. In the north American context, in particular, it may be the case that inadequate data have been over enthusiastically interpreted. Alternatively, objections may have been voiced more forcefully in north America than elsewhere to the phenomenon of epidemiologists getting involved in policy.

On the one hand, it seems to me a simple thing (not simplistic, I hope) to say that all information relating to health and disease should be examined to see if there might be public policy implications-how can researchers be responsible citizens otherwise? On the other hand, to imply that all such information, whether clinical or epidemiological (to use broad categories which are not mutually exclusive), must have unequivocal policy implications seems absurd. Surely a rational intermediate position is possible.

A review article by Murphy and Davey Smith in February 1997 traced the development of the content of this Journal from the earliest days (when it was the British fournal of Social Medicine) to recent times. ${ }^{1}$ The authors expressed concern about the apparent lack of impact of many or most of the published papers, but expressed some optimism for the future. When I became Editor in 1993 I introduced three main sections for Journal papers, excluding editorial comment and review articles, namely Epidemiology, Health services research, and Methods. Clearly I will be in real danger of oversimplifying matters if I try to equate "having impact" with "being useful"; I will be even more at risk if I allege that what I have as Editor put into the Health services research category rather than the Epidemiology or Methods categories is what is "useful". But I can ask readers-and authors who submit papers-to note the views of myself and my Associate Editor: many of the papers which we reject or which are rated as of low priority (and don't rise sufficiently high up the list to attain publication) are descriptive studies, epidemiology or health service related, which have little obvious relevance to policy, whether that policy relates to prevention or to effectiveness.

The breakdown of how much health services research has been published over the past five years is as follows (excluding this month's journal):

- Out of 440 papers published, 103 (23\% of papers, $24 \%$ of pages) have been labelled Health services research. (14\% were Methods papers, leaving $63 \%$ as Epidemiology papers.)

- In 1996 and 1997 combined the maximum proportion of $28 \%$ of papers and pages were attained by the Health services research papers.

My personal hope is that more and more epidemiology papers will attempt to address policy issues, albeit with modesty and caution. Key points are intended to focus the attention of authors, just as much as readers, on the "so what?" questions.

A new Editor will assume responsibility for the monthly $\mathcal{F E C H}$ from the beginning of 1998 . I myself will be moving from a university post (I have worked since 1970 in different university departments) to the National Health Service, where I will (I trust) enjoy participation in policy development and implementation with a solid epidemiological base. Since I am retiring in several senses (but not all) I hope that readers will indulge me as I express my sincere hopes that this Journal (and similar ones) will maintain and increase their impact in disseminating epidemiological ideas and results which will be really useful (even if not musically so) in contributing to the protection and promotion of the health and welfare of the widely different populations and communities of which we are part.

STUART DONNAN Editor 1 Murphy S, Davey Smith G. The British Journal of Social Medicine: what was
in a name? $\mathcal{F}$ Epidemiol Community Health 1997;51:2-8. 